\title{
The Perilous PPI: Proton Pump Inhibitor as a Cause of Clinically Significant Hypomagnesaemia
}

\author{
Yong Ting Tai and Chin Vong Tong \\ Department of Medicine, Hospital Melaka, Malaysia
}

\begin{abstract}
Proton pump inhibitors (PPIs) are the mainstay of therapy for all gastric acid related diseases and are commonly used in current clinical practice. Although widely regarded as safe, PPIs have been associated with a variety of adverse effects, including hypomagnesaemia. The postulated mechanism of PPI-related hypomagnesaemia involves inhibition of intestinal magnesium absorption via transient receptor potential melastin (TRPM) 6 and 7 cation channels. PPI-induced hypomagnesaemia (PPIH) has become a well recognized phenomenon since it was first reported in 2006. Clinical concerns arise from growing number of case reports presenting PPIH as a consequence of long-term PPI use, with more than 30 cases published to date.
\end{abstract}

In this article, we report 2 cases of PPIH associated with the use of pantoprazole. Both patients presented with severe hypomagnesaemia and hypocalcaemia. One of them had associated hypokalemia and cardiac arrhythmia. A casual relation with PPIs postulated and supported by resolution of electrolyte abnormalities after discontinuation of PPIs.

Key words: Proton pump inhibitors, hypomagnesaemia, hypocalcaemia, hypokalemia

\section{INTRODUCTION}

Proton pump inhibitors (PPIs) are the mainstay of therapy for all gastric acid related diseases and are commonly used in current clinical practice. Although widely regarded as safe, PPIs have been associated with a variety of adverse effects including interstitial nephritis, pneumonia, Clostridium difficile-associated diarrhea, vitamin B12 deficiency, osteoporosis and fractures. ${ }^{1}$ More recently, long-term use of PPIs has been suggested as a potential cause of hypomagnesaemia ${ }^{2}$ Magnesium is the second most abundant intracellular cation and its homeostasis is intricately regulated by intestinal absorption and renal excretion. The postulated mechanism of PPI-related hypomagnesaemia involves inhibition of intestinal magnesium absorption via transient receptor potential melastin (TRPM) 6 and 7 cation channels. ${ }^{3,4}$ Severe hypomagnesaemia can be associated with malignant cardiac arrhythmias, tetany, generalized seizures, and other metabolic disturbances such as hypokalemia and hypocalcaemia. ${ }^{5}$

PPI-induced hypomagnesaemia (PPIH) has become a well recognized phenomenon since it was first reported in 2006. ${ }^{6}$ Clinical concerns arise from growing number of case reports presenting $\mathrm{PPIH}$ as a consequence of longterm PPI use, with more than 30 cases published to date. - $^{-}$ ${ }^{22}$ In 2011, United States Food and Drug Administration released a safety concern on PPIs, stating that it may cause hypomagnesaemia if taken for prolonged periods of time. ${ }^{23}$ This announcement alerted healthcare professionals to the risk of hypomagnesaemia among chronic PPI users, with the consideration of obtaining baseline and regular follow-up serum magnesium concentrations over time. In this article, we report 2 cases of PPIH associated with the use of pantoprazole.

\section{CASE 1}

Patient 1 was a 59-year-old female with a background history of diabetes mellitus and hypertension. Her medications included perindopril, amlodipine, metformin and gliclazide. She was diagnosed with pulmonary tuberculosis one month prior to admission (PTA), having presented with 3-month history of fever, cough and constitutional symptoms. She was started on antituberculosis treatment. Unfortunately, she developed epigastric pain and vomiting and was started on pantoprazole a month later. She requested at-own-risk discharge from hospital on two days after starting the PPI.

Three days later, she was admitted again due to persistent vomiting and epigastric pain. On her $1^{\text {st }}$ hospital day (HD) she developed an episode of narrow-complex tachycardia with prolonged QTC and went into respiratory distress. She required intubation and was transferred to the intensive care unit. Her blood investigations showed multiple electrolyte abnormalities, including hypomagnesaemia, hypocalcaemia, hypophosphatemia and hypokalemia. She was given multiple doses of parenteral magnesium sulfate, calcium gluconate and potassium chloride to correct those deficiencies. However, the serum magnesium, 
potassium and calcium levels failed to return to normal despite multiple corrections given.

On the $3^{\text {rd }} \mathrm{HD}$, pantoprazole was discontinued. Thereafter, the serum levels of magnesium, potassium and calcium started to respond to the IV corrections and slowly returned to normal. (Table 1 and Figure 1). Unfortunately, the patient developed hospital-acquired pneumonia and succumbed to septicemia two weeks later.

\section{CASE 2}

Patient 2 is a 71-year-old female. She had underlying diabetes mellitus, hypertension, chronic kidney disease (CKD) stage $\mathrm{V}$ (not on renal replacement therapy) and bilateral knee osteoarthritis. She was diagnosed with peptic ulcer disease in 5 months PTA after an episode of upper gastrointestinal bleeding. She was prescribed pantoprazole since that admission. On the day of admission, she presented with lethargy and bilateral hand numbness. Blood investigations showed she had severe hypocalcaemia and hypomagnesaemia. Her pantoprazole was withheld on her $2^{\text {nd }} \mathrm{HD}$ and substituted with oral ranitidine. She was given a few intravenous calcium and magnesium corrections. Her serum magnesium and calcium levels slowly returned to near normal levels after the pantoprazole was discontinued (Table 2 and Figure 2). She was discharged on her $6^{\text {th }} \mathrm{HD}$ with oral calcium carbonate supplement. When she followed up one month later, her blood magnesium and calcium levels had normalized. Vitamin D level was not available due to reagent shortage.

\section{DISCUSSION}

We describe two adult patients presenting with severe hypomagnesaemia and hypocalcaemia while using PPIs. Patient 1 developed hypomagnesaemia and hypocalcaemia after short-term use of pantoprazole of 7 days while patient 2 experienced the same side effects after 4 months. This is consistent with the findings in a systematic review published by Hess et al, in which the time to onset of hypomagnesaemia is highly variable and ranged from 14 days up to 13 years (mean 5.5 years)..$^{7}$ This finding suggests that serum magnesium and calcium levels should be frequently monitored in patients taking PPIs, regardless of the duration of medication given.

Recent studies postulated that the potential mechanism for PPIH is not due to renal magnesium wasting, but rather decreased gastrointestinal absorption, evidenced by reduced urinary excretion of magnesium in the setting of PPIH. ${ }^{6-9}$ Few recent mechanistic studies which have focused on the potential effect of PPI use on the TRMP6 transporter, the main pathway of magnesium absorption in the intestine, supports the above clinical observations. TRPM6 activity is regulated by intracellular magnesium along with $\mathrm{pH}^{24,25}$ A more acidic environment will increase TRPM6 activity. PPI therapy decreases gastric acid secretion, increasing lumen $\mathrm{pH}$, and therefore decreases TRPM6 activity, which results in decreased intestinal magnesium absorption. ${ }^{26-28}$ Our patient 1 showed similar pattern, in which during the hypomagnesaemia state, the urine excretion of magnesium was reduced to conserve magnesium. For patient 2, unfortunately, no 24-hour urine magnesium was sent.

Table 1. Patient 1 blood investigations

\begin{tabular}{|c|c|c|c|c|c|c|c|c|}
\hline \multirow[b]{2}{*}{ Date } & \multirow{2}{*}{$\begin{array}{c}\text { Baseline } \\
27 / 8 / 17\end{array}$} & \multicolumn{2}{|c|}{ On pantoprazole } & \multicolumn{5}{|c|}{ Pantoprazole discontinued } \\
\hline & & $19 / 9 / 17$ & $20 / 9 / 17$ & $21 / 9 / 17$ & $22 / 9 / 17$ & $24 / 9 / 17$ & $27 / 9 / 17$ & 29/9/17 \\
\hline Corrected calcium (2.18-2.6 mmol/L) & 2.22 & 1.5 & 1.5 & 1.46 & 2.0 & 2.02 & 1.96 & 2.26 \\
\hline Magnesium (0.53-1.11 mmol/L) & 0.75 & 0.35 & - & 0.74 & 0.85 & 0.78 & 0.74 & 0.65 \\
\hline Phosphate (0.78-1.65 mmol/L) & 0.83 & 0.7 & 0.48 & 0.12 & 0.66 & 0.86 & 1.01 & 0.57 \\
\hline Potassium (3.5-5.1 mmol/L) & 4.6 & 3.0 & 3.3 & 3.6 & 4.1 & 4 & 3.3 & 4.4 \\
\hline $\begin{array}{l}\text { iPTH: } \\
24 \text { hour urine calcium: } \\
24 \text { hour urine magnesium: } \\
\text { Total } 25 \text {-hydroxyVitamin D: }\end{array}$ & $\begin{array}{l}7.45 \mathrm{pmol} / \mathrm{L} \\
0.15 \mathrm{mmol} / 24 \text { hour } \\
3.4 \mathrm{mmol} / 24 \text { hour } \\
46.94 \mathrm{nmol} / \mathrm{L}\end{array}$ & $\begin{array}{l}(1.58-6.03) \\
(2.5-7.5) \\
(4.0-5.0) \\
(<25 \text { Defici } \\
(25-75 \text { Ins } \\
(75-250 \mathrm{Su} \\
(>250 \text { Pos }\end{array}$ & $\begin{array}{l}\text { ent) } \\
\text { ent) } \\
\text { intoxicat }\end{array}$ & & & & & \\
\hline
\end{tabular}

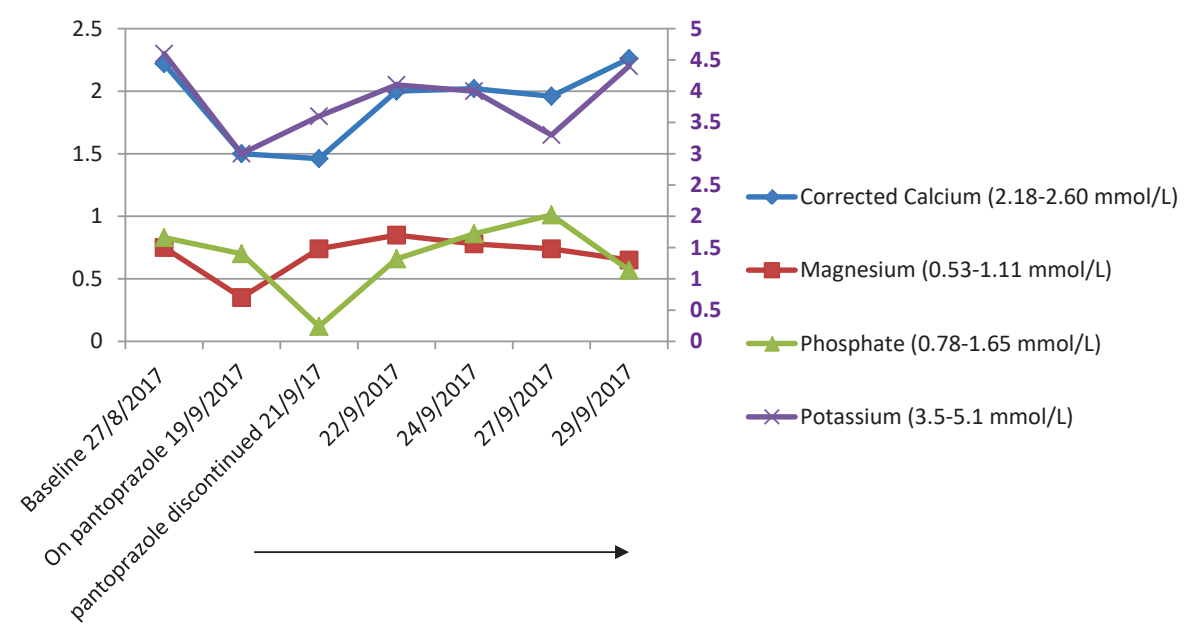

Figure 1. Course of laboratory parameters over time in patient 1. 
Table 2. Patient 2 blood investigations

\begin{tabular}{|c|c|c|c|c|c|c|c|}
\hline \multirow[b]{2}{*}{ Date } & \multirow[b]{2}{*}{$11 / 9 / 18$} & \multicolumn{6}{|c|}{ Pantoprazole discontinued } \\
\hline & & $13 / 9 / 18$ & $14 / 9 / 18$ & $15 / 9 / 18$ & $16 / 9 / 18$ & $17 / 9 / 18$ & $17 / 10 / 18$ \\
\hline Corrected calcium (2.18-2.6 mmol/L) & 1.35 & 1.54 & 1.63 & 1.73 & 1.91 & 1.96 & 2.29 \\
\hline Magnesium (0.53-1.11 mmol/L) & 0.42 & 0.48 & 0.53 & 0.46 & 0.52 & 0.77 & 0.81 \\
\hline Phosphate (0.78-1.65 mmol/L) & 1.47 & 1.44 & 1.33 & 1.58 & 1.63 & 1.58 & - \\
\hline Potassium (3.5-5.1 mmol/L) & 4.3 & - & - & 4.4 & 4.6 & 4.6 & - \\
\hline
\end{tabular}

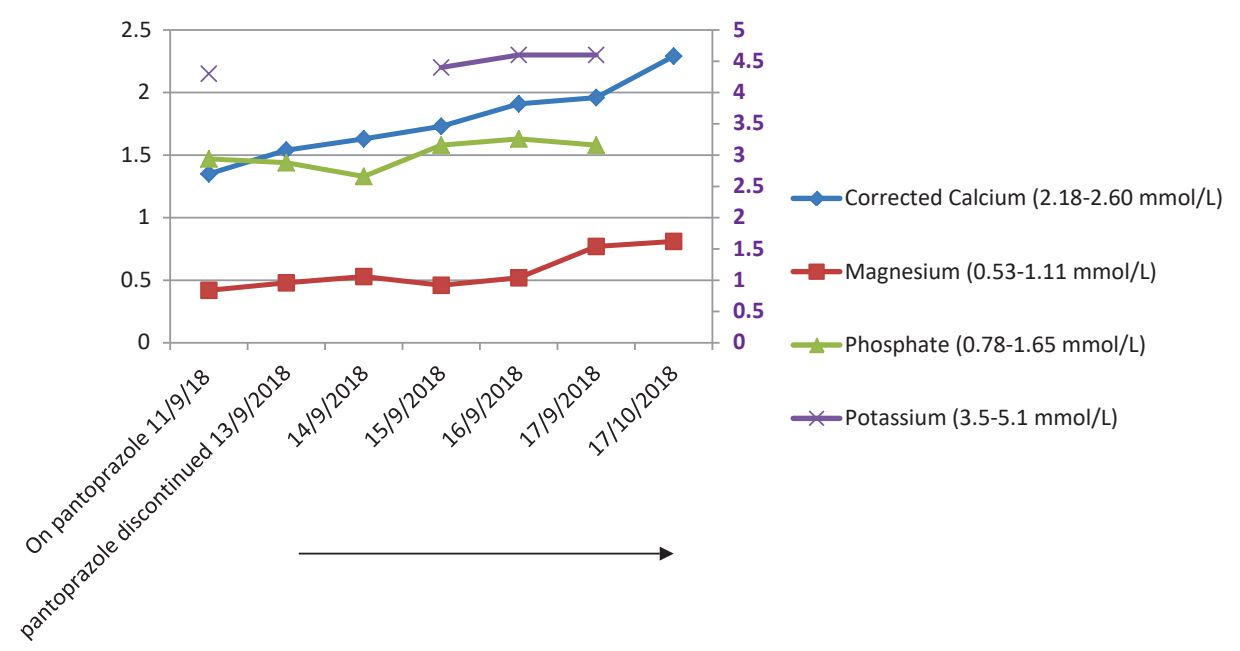

Figure 2. Course of laboratory parameters over time in patient 2.

Hypomagnesaemia is commonly asymptomatic and the most common signs of magnesium deficiency are hypokalemia and hypocalcaemia. Patients with symptomatic hypomagnesaemia will most commonly present with neuromuscular irritability or cardiac arrhythmia $^{29}$ as was the case with our patient 1 who presented with a narrow complex tachycardia with prolonged QT.

As mentioned above, the most classical sign of severe hypomagnesaemia is hypocalcaemia. Adequate amount of magnesium is essential for vitamin D and calcium homeostasis ${ }^{30}$ and function of the parathyroid glands. Magnesium deficiency affects the function of phosphatidylinositol system and adenylate cyclase activity in parathyroid glands and in target tissues. ${ }^{31-36}$ As a result, this will lead to:

1. Reduced secretion of parathyroid hormone (PTH), leading to reduced bone resorption, reduced intestinal calcium absorption, and increased renal calcium loss. Collectively, these will lead to hypocalcaemia.

2. Reduced target tissue sensitivity to PTH. When bone and kidney tissues are resistant to PTH, PTH mediated $1 \alpha$-hydroxylation of vitamin D decreases. ${ }^{37}$ This will lead to a decrease in intestinal absorption of calcium and result in hypocalcaemia.

In patient 1 , we noted magnesium-dependent PTH suppression with development of transient hypoparathyroidism and severe hypocalcaemia (the iPTH level $7.45 \mathrm{pmol} / \mathrm{L}$ is only mildly increased, which is inappropriate in the setting of severe hypocalcaemia in patient 1). After the magnesium level was corrected, hypocalcemia in patient 1 slowly resolved. This confirmed that hypomagnesaemia is the cause of the transient hypoparathyroidism and hypocalcaemia in patient 1 . On the other hand, in patient 2, the iPTH level was high (22.78
pmol/L) instead of low. Patient 2 had CKD stage 5, she might have concurrent secondary hyperparathyroidism due to CKD and therefore the iPTH level was elevated.

Patient 1 was noted to have concurrent vitamin $\mathrm{D}$ deficiency. This is not an uncommon finding among Malaysian women as the prevalence of vitamin D deficiency is high in Malaysia. ${ }^{38}$ Concurrent vitamin D deficiency in patient 1 could also be contributing to her hypocalcaemia. For patient 2, unfortunately no vitamin D level was sent.

Hypokalemia is a common event in patients with hypomagnesaemia, occurring in 40 to 60 percent of cases. ${ }^{39}$ Hypomagnesaemia is associated with a reduction in intracellular magnesium concentration, which may then lead to a decline in adenosine triphosphate (ATP) activity. This decline removes the ATP inhibition of potassium (ROMK) channels, leading to an increase in the number of these channels. The uninhibited potassium channels will therefore increase potassium secretion from the cell into the lumen in the cells of the thick ascending limb and cortical collecting tubule, and cause renal potassium wasting and eventually lead to hypokalemia. ${ }^{40-42}$ As a result, hypokalemia is resistant to potassium supplement and can be treated only by correcting the magnesium deficit. In patient 1, the hypokalemia was initially resistant to potassium correction. After pantoprazole was discontinued and the magnesium deficit corrected, the potassium level normalized. In patient 2, no hypokalemia was noted, possibly because patient 2 had advanced chronic kidney disease with reduced kidney excretion of potassium, which neutralized the hypokalemia caused by magnesium deficiency.

The treatment of PPIH is similar to that of other forms of hypomagnesaemia, in which parenteral magnesium is indicated in severe hypomagnesaemia. However, 
intravenous magnesium replacement is only partially effective and provides only short-term relief, while PPI therapy is maintained. This is because PPI-induced blockade in magnesium absorption cannot be overcome by magnesium supplement alone. The struggle to reverse the hypomagnesaemia in these 2 patients while still on pantoprazole improved after pantoprazole was discontinued. This finding is consistent with previous case reports and systematic review. ${ }^{6-22}$ The only effective way to reverse PPIH is discontinuation of PPIs.

PPIH is observed for all currently available PPIs and appear to be a class effect. Discontinuation of PPIs leads to fast recovery from PPIH. However, it reappears invariably when rechallenged with the same or a different PPI. Fortunately, it does not occur with other acid suppressants such as $\mathrm{H} 2$ receptor antagonists $\left(\mathrm{H}_{2} \mathrm{RA}\right)^{6-22}$ as seen in patient 2. Her pantoprazole was substituted with ranitidine. During her clinic follow up a month later, her magnesium and calcium levels remained normal. Therefore, in patients with gastric acid related disease that is complicated with PPIH, $\mathrm{H}_{2} \mathrm{RA}$ should be considered and we should avoid rechallenge with the same or a different PPI.

The prevalence of PPI-induced hypomagnesaemia is not known. Case reports and case series to date only represent the tip of the iceberg. Symptoms of hypomagnesaemia are either non-specific or could be misinterpreted. Therefore, proper identification and treatment of PPIH mainly rests on 3 principles:

1. The need for long-term PPI therapy in patients should be kept under regular review.

2. If PPI therapy is required on a long-term basis, serum magnesium monitoring should be performed on a regular basis. If $\mathrm{PPIH}$ develops, discontinuation of PPIs, supported by magnesium supplement, will lead to rapid normalization of serum magnesium.

3. Patients with PPIH can avoid hypomagnesaemia by using alternative acid suppressants. Therefore, $\mathrm{H}_{2} \mathrm{RA}$ should be considered in the event of PPIH.

\section{CONCLUSION}

In conclusion, known risks of long-term PPI administration must be considered in clinical practice and judicious use of PPIs is important to avoid potentially fatal complications.

\section{Acknowledgment}

The authors would like to thank the Director General of Health Malaysia for his permission to publish this article.

\section{Ethical Consideration}

Ethical clearance has been obtained by the authors. The Chief Health Director of Malaysia has approved the publication of the manuscript. The manuscript will also be submitted to the Scientific Unit of Communication and Distribution, the National Institute after its publication.

\section{Statement of Authorship}

All authors certified fulfillment of ICMJE authorship criteria.

\section{Author Disclosure}

The authors declared no conflict of interest.

\section{Funding Source}

None.

\section{References}

1. Kinoshita Y, Ishimura N, Ishihara S. Advantages and disadvantages of long-term proton pump inhibitor use. J Neurogastroenterol Motil. 2018;24(2):182-96. PMID: 29605975. PMCID: PMC5885718. https:// doi.org/10.5056/jnm18001.

2. Famularo G, Gasbarrone L, Minisola G. Hypomagnesaemia and proton-pump inhibitors. Expert Opin Drug Saf. 2013;12(5):709-16 PMID: 23808631. https://doi.org/10.1517/14740338.2013.809062.

3. Schlingmann KP, Waldegger S, Konrad M, Chubanov V, Gudermann T. TRPM6 and TRPM7-Gatekeepers of human magnesium metabolism. Biochim Biophys Acta. 2007;1772(8): 813-21. PMID: 17481860. https://doi.org/10.1016/j.bbadis.2007.03.009.

4. William JH, Danziger J. Proton-pump inhibitor-induced hypomagnesaemia: Current research and proposed mechanisms. World J Nephrol. 2016;5(2): 152-7. PMID: 26981439. PMCID: PMC4777786. https://doi.org/10.5527/wjn.v5.i2.152.

5. Weisinger JR, Bellorin-Font E. Magnesium and phosphorus. Lancet. 1998;352(9125):391-6. PMID: 9717944. https://doi.org/10.1016/ S0140-6736(97)10535-9.

6. Epstein M, McGrath S, Law F. Proton-pump inhibitors and hypomagnesemic hypoparathyroidism. N Engl J Med. 2006;355(17): 1834-6. PMID: 17065651. https://doi.org/10.1056/NEJMc066308.

7. Hess MW, Hoenderop JG, Bindels RJ, Drenth JP. Systematic review: Hypomagnesaemia induced by proton pump inhibition. Aliment Pharmacol Ther. 2012;36(5):405-13. PMID: 22762246. https:/doi. org/10.1111/j.1365-2036.2012.05201.x.

8. Cundy T, Dissanayake A. Severe hypomagnesaemia in long-term users of proton-pump inhibitors. Clin Endocrinol (Oxf). 2008;69(2):338-41. PMID: 18221401. https://doi/org/10.1111/j.1365-2265.2008.03194.x.

9. Hoorn EJ, van der Hoek J, de Man RA, Kuipers EJ, Bolwerk C, Zietse R. A case series of proton pump inhibitor-induced hypomagnesaemia. Am J Kidney Dis. 2010;56(1):112-6. PMID: 20189276. https://doi.org/10.1053/j.ajkd.2009.11.019.

10. Fernández-Fernández FJ, Sesma P, Caínzos-Romero T, FerreiraGonzález L. Intermittent use of pantoprazole and famotidine in severe hypomagnesaemia due to omeprazole. Neth J Med. 2010;68(10):329-30. PMID: 21071783.

11. Shabajee N, Lamb EJ, Sturgess I, Sumathipala RW. Omeprazole and refractory hypomagnesaemia. BMJ. 2008;337:a425. PMID: 18617497. PMCID: PMC2483862. https://doi.org/10.1136/bmj.39505.738981.BE.

12. Arulanantham N, Anderson M, Gittoes N, Ferner RE. A 63-yearold man with hypomagnesaemia and seizures. Clin Med (Lond). 2011;11(6):591-3. PMID: 22268316 PMCID: PMC4952343. https:// doi.org/10.7861/clinmedicine.11-6-591.

13. Famularo G, Minisola G, Bravi MC, Colucci P, Gasbarrone L. Tetany, hypomagnesaemia, and proton-pump inhibitors. Am J Med. 2012; 125(10):e7-8. PMID: 22800870. https://doi.org/10.1016/ j.amjmed.2012.04.027.

14. Broeren M, Geerdink E, Vader HL, van den Wall Bake AW. Hypomagnesaemia induced by several proton-pump inhibitors. Ann Intern. 2009; 151(10): 755-6. PMID: 19920278. https://doi org/10.7326/0003-4819-151-10-200911170-00016.

15. Mackay JD, Bladon PT. Hypomagnesaemia due to proton-pump inhibitor therapy: A clinical case series. QJM. 2010;103(6): 387-95. PMID: 20378675. https://doi.org/10.1093/qjmed/hcq021.

16. Kuipers MT, Thang HD, Arntzenius AB. Hypomagnesaemia due to use of proton pump inhibitors-A review. Neth J Med 2009; 67:169-72. PMID: 19581665.

17. Furlanetto TW, Faulhaber GAM. Hypomagnesaemia and proton pump inhibitors: Below the tip of the iceberg. Arch Intern Med. 2011; 171(15): 1391-2. PMID: 21555654. https://doi.org/10.1001/ archinternmed.2011.199

18. Matsuyama J, Tsuji K, Doyama H, Kim F, Takeda $\mathrm{Y}$, et al Hypomagnesaemia associated with a Proton Pump Inhibitor. Intern Med. 2012; 51(16): 2231-4. PMID: 22892510. https://doi.org/10.2169/ internalmedicine.51.7748.

19. Gandhi NY, Sharif WK, Chadha S, Shakher J. A patient on longterm proton pump inhibitors develops sudden seizures and encephalopathy: An unusual presentation of hypomagnesaemia. Case Rep Gastrointest Med. 2012; 2012:632721. PMID: 23213582. PMCID: PMC3506867. https://doi.org/10.1155/2012/632721.

20. Egshatyan LV. Functional hypoparathyroidism secondary to magnesium deficiency in long-term users of proton pump inhibitor: case report. Osteopo Bone Dis. 2017; 20(3):102-7. https://doi. org/10.14341/osteo20173102-107.

21. François M, Lévy-Bohbot N, Caron J, Durlach V. Chronic use of proton-pump inhibitors associated with giardiasis: A rare cause of hypomagnesemic hypoparathyroidism? Ann Endocrinol (Paris). 2008;69(5):446-8. PMID: 18614153. https://doi.org/10.1016/ j.ando.2008.03.003.

22. Regolisti G, Cabassi A, Parenti E, Maggiore U, Fiaccadori E. Severe hypomagnesaemia during long-term treatment with a proton pump inhibitor. Am J Kidney Dis. 2010;56(1):168-74. PMID: 20493607. https://doi.org/10.1053/j.ajkd.2010.03.013. 
23. FDA Drug Safety Communication: Low magnesium levels can be associated with long-term use of proton pump inhibitor drugs (PPIs). Available from URL: https:/www.fda.gov/drugs/ drugsafety/ucm245011.htm. Accessed on December 18, 2018

24. Voets $\mathrm{T}$, Nilius $\mathrm{B}$, Hoefs $\mathrm{S}$, et al. TRPM6 forms the Mg2+ influx channel involved in intestinal and renal $\mathrm{Mg} 2+$ absorption. J Biol Chem. 2004;279(1):19-25. PMID: 14576148. https://doi.org/10.1074/ jbc.M311201200.

25. Thébault S, Cao G, Venselaar H, Xi Q, Bindels RJ, Hoenderop JG Role of the alpha-kinase domain in transient receptor potential melastatin 6 channel and regulation by intracellular ATP. J Biol Chem. 2008;283(29):19999-20007. PMID: 18490453. https://doi. org/10.1074/jbc.M800167200.

26. Lameris AL, Hess MW, van Kruijsbergen I, Hoenderop JG, Bindels RJ. Omeprazole enhances the colonic expression of the $\mathrm{Mg}(2+)$ transporter TRPM6. Pflugers Arch. 2013;465(11):1613-20. PMID: 23756852. https://doi.org/10.1007/s00424-013-1306-0.

27. Li M, Du J, Jiang J, Ratzan W, Su LT, Runnels LW, Yue L. Molecular determinants of $\mathrm{Mg} 2+$ and $\mathrm{Ca} 2+$ permeability and $\mathrm{pH}$ sensitivity in TRPM6 and TRPM7. J Biol Chem. 2007;282(35): 25817-30. PMID: 17599911. PMCID: PMC3239414. https://doi.org/10.1074/jbc M608972200.

28. Groenestege WM, Hoenderop JG, van den Heuvel L, Knoers N, Bindels RJ. The epithelial Mg2+ channel transient receptor potential melastatin 6 is regulated by dietary $\mathrm{Mg} 2+$ content and estrogens. J Am Soc Nephrol 2006;17(4):1035-43. PMID: 16524949. https://doi. org/10.1681/ASN.2005070700.

29. Agus ZS. Hypomagnesemia. J Am Soc Nephrol. 1999;10(7):1616-22. PMID: 10405219.

30. Deng X, Song Y, Manson JE, et al. Magnesium, vitamin D status and mortality: Results from US National Health and Nutrition Examination Survey (NHANES) 2001 to 2006 and NHANES III. BMC Med. 2013;11:187. PMID: 23981518. PMCID: PMC3765911. https://doi.org/10.1186/1741-7015-11-187.

31. Litosch I. G protein regulation of phospholipase C activity in a membrane-solubilized system occurs through a $\mathrm{Mg} 2(+)-$ and time dependent mechanism. J Biol Chem. 1991; 266(8):4764-71. PMID: 2002026.

32. Northup JK, Smigel MD, Gilman AG. The guanine nucleotide activating site of the regulatory component of adenylate cyclase. Identification by ligand binding. J. Biol. Chem. 1982;257(19): 11416-23. PMID: 6288684.
33. Volpe $\mathrm{P}$, Alderson-Lang $\mathrm{BH}$, Nickols GA. Regulation of inositol 1,4,5-trisphosphate-induced Ca2+ release. I. Effect of Mg2+. Am J Physiol. 1990;258(6 Pt 1): C1077-85. https://doi.org/10.1152/ajpcell. 1990.258.6.C1077.

34. Rude RK, Oldham SB, Sharp CF Jr., Singer FR. Parathyroid hormone secretion in magnesium deficiency. J Clin Endocrinol Metab. 1978;47(4):800-6. PMID: 263326. https://doi.org/10.1210/ jcem-47-4-800.

35. Freitag JJ, Martin KJ, Conrades MB, et al. Evidence for skeletal resistance to parathyroid hormone in magnesium deficiency. J Clin Invest.1979;64(5):1238-44. PMID: 227929. PMCID: PMC371269. https://doi.org/10.1172/JCI109578.

36. Rude RK, Oldham SB, Singer FR. Functional hypoparathyroidism and parathyroid hormone end-organ resistance in human magnesium deficiency. Clin Endocrinol (Oxf). 1976;5(3):209-24. PMID: 182417. https://doi.org/10.1111/j.1365-2265.1976.tb01947.x.

37. Fatemi S, Ryzen E, Flores J, Endres DB, Rude RK. Effect of experimental human magnesium depletion on parathyroid hormone secretion and 1,25-dihydroxyvitamin D metabolism. J Clin Endocrinol Metabol. 1991;73(5):1067-72. PMID: 1939521. https://doi.org/10.1210/ jcem-73-5-1067.

38. Rahman SA, Chee WS, Yassin Z, Chan SP. Vitamin D status among postmenopausal Malaysian women. Asia Pac J Clin Nutr. 2004;13(3):255-60. PMID: 15331337.

39. Whang R, Ryder KW. Frequency of hypomagnesaemia and hypermagnesemia. Requested vs routine. JAMA. 1990; 263(22): 3063-4. PMID: 2342219.

40. Huang CL, Kuo E. Mechanism of hypokalemia in magnesium deficiency. J Am Soc Nephrol. 2007; 18(10): 2649-52. PMID: 17804670. https://doi.org/10.1681/ASN.2007070792.

41. Nichols CG, Ho $\mathrm{K}$, Hebert $\mathrm{S}$. $\mathrm{Mg}(2+)$-dependent inward rectification of ROMK1 potassium channels expressed in Xenopus oocytes. J Physiol. 1994 May; 476(3): 399-409. PMID: 8057249. PMCID: PMC1160454. https://doi.org/10.1113/jphysiol.1994.sp02014.

42. Yang L, Frindt G, Palmer LG. Magnesium modulates ROMK channel-mediated potassium secretion. J Am Soc Nephrol. 2010;21(12):2109-16. PMID: 21030597. PMCID: PMC3014024. https:// doi.org/10.1681/ASN.2010060617.

Authors are required to accomplish, sign and submit scanned copies of the JAFES Author Form consisting of: (1) Authorship Certification, that authors contributed substantially to the work, that the manuscript has been read and approved by all authors, and that the requirements for authorship have been met by each author; (2) the Author Declaration, that the article represents original material that is not being considered for publication or has not been published or accepted for publication elsewhere, that the article does not infringe or violate any copyrights or intellectual property rights, and that no references have been made to predatory/ suspected predatory journals; (3) the Author Contribution Disclosure, which lists the specific contributions of authors; and (4) the Author Publishing Agreement which retains author copyright, grants publishing and distribution rights to JAFES, and allows JAFES to apply and enforce an Attribution-Non-Commercial Creative Commons user license. Authors are also required to accomplish, sign, and submit the signed ICMJE form for Disclosure of Potential Conflicts of Interest. For original articles, authors are required to submit a scanned copy of the Ethics Review Approval of their research as well as registration in trial registries as appropriate. For manuscripts reporting data from studies involving animals, authors are required to submit a scanned copy of the Institutional Animal Care and Use Committee approval. For Case Reports or Series, and Images in Endocrinology, consent forms, are required for the publication of information about patients; otherwise, appropriate ethical clearance has been obtained from the institutional review board. Articles and any other material published in the JAFES represent the work of the author(s) and should not be construed to reflect the opinions of the Editors or the Publisher.

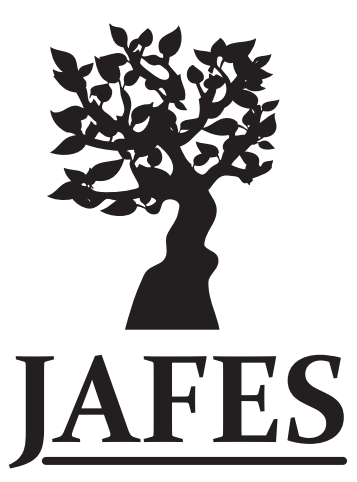

\section{Unique, interesting, enlightening. Your case report and the JAFES.}

